\title{
Erratum to: Development and evaluation of methods for starch dissolution using asymmetrical flow field-flow fractionation. Part II: dissolution of amylose
}

\author{
Daysi Perez-Rea $^{1,2} \cdot$ Björn Bergenståhl $^{1} \cdot$ Lars Nilsson $^{1}$
}

Received: 13 November 2015 / Accepted: 13 November 2015 /Published online: 30 December 2015

(C) Springer-Verlag Berlin Heidelberg 2015

Erratum to: Anal Bioanal Chem

DOI 10.1007/s00216-015-8894-9

The original version of this article unfortunately contained a mistake. The presentation of Fig. 4 was incorrect. The correct version of Fig. 4 is given below and the original article was corrected. with guest editors Gaetane Lespes, Catia Contado, and Bruce Gale.

The online version of the original article can be found at http://dx.doi.org/ 10.1007/s00216-015-8894-9.

Lars Nilsson

lars.nilsson@food.lth.se

1 Food Colloids Group, Department of Food Technology, Engineering and Nutrition, Faculty of Engineering LTH, Lund University, PO Box 124, 22100 Lund, Sweden

2 Centro de Alimentos y Productos Naturales, Universidad Mayor de San Simón, Calle Sucre y parque La Torre, Cochabamba, Bolivia 

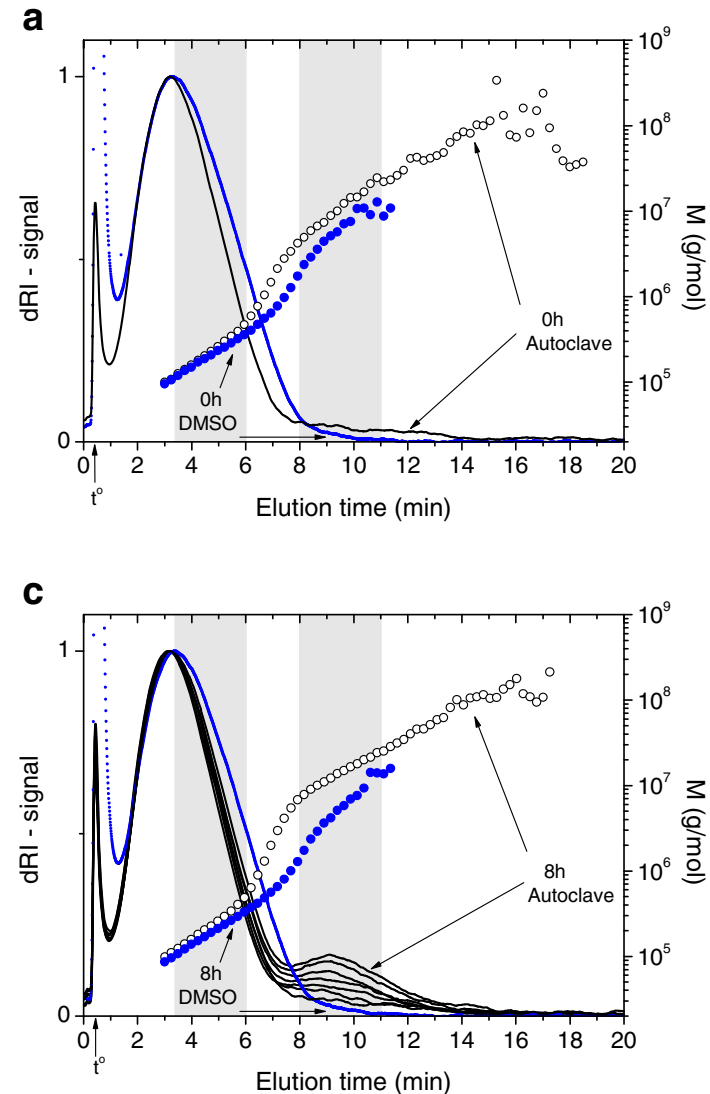

Fig. 4 Comparison of autoclave (black) and DMSO (blue) dissolution methods for the potato amylose (the shaded areas correspond to apparent density plots in Figure 5). a dRI-signal (line) and molar mass (symbols) vs. elution time; $\mathbf{b}$ MALS signal (lines) and $\mathrm{r}_{\mathrm{rms}}($ symbols) vs. elution time
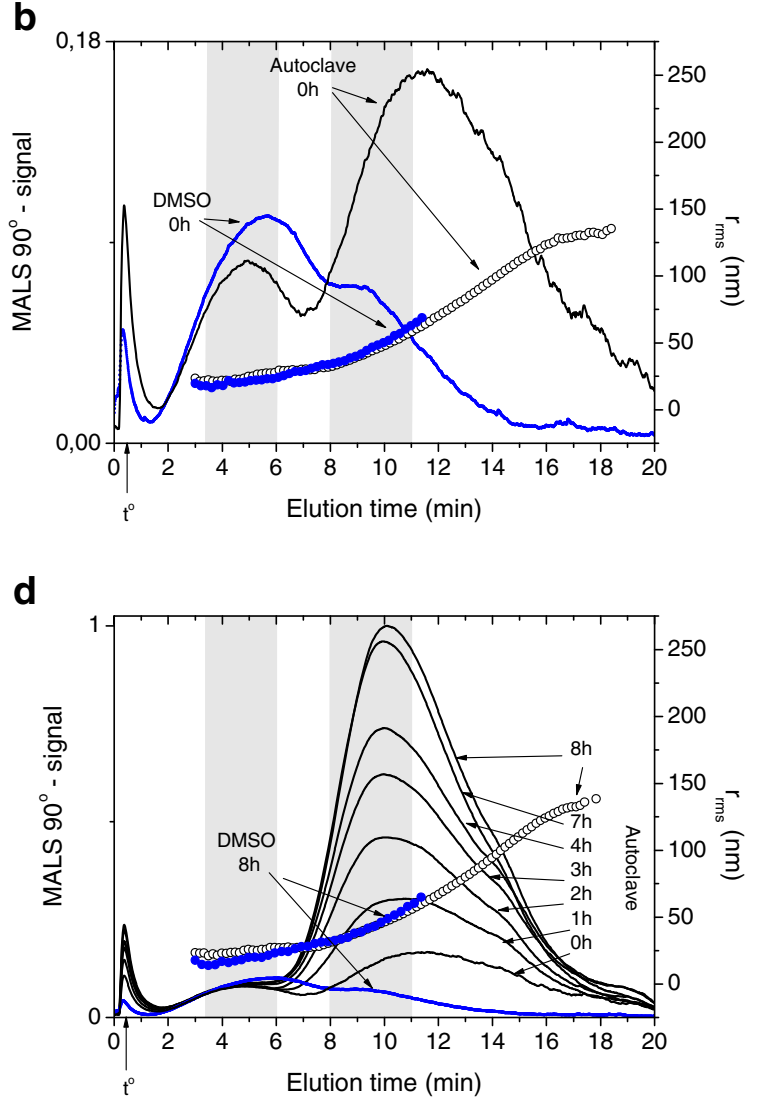

for samples injected immediately after dissolution; c dRI signal (lines) and molar mass (symbols) vs. elution time; d MALS-signal (lines) and $\mathrm{r}_{\mathrm{rms}}$ (symbols) vs. elution time for samples injected 0-8h after dissolution 